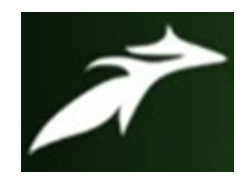

S. Sandhiya et al, International Journal of Advances in Agricultural Science and Technology,

Vol.8 Issue.1, January-2021, pg. 139-148

ISSN: 2348-1358

Impact Factor: 6.057

NAAS Rating: 3.77

\title{
KSAN (KISAN SOIL ANALYSING NETWORK)
}

\author{
S. Sandhiya ${ }^{1}$; K. Sowmika ${ }^{1}$; S.M. Amsa Varshini ${ }^{1}$ \\ UG Students, Dept. of Agriculture Engineering, Nandha Engineering College, Perundurai, Erode, Tamil Nadu, India ${ }^{1}$ \\ N.Manimekalai ${ }^{2}$ \\ Associate Prof., Dept. of Agriculture Engineering, Nandha Engineering College, Perundurai, Erode, Tamil Nadu, India ${ }^{2}$ \\ sandhiya.17ag045@nandhaengg.org \\ DOI: 10.47856/ijaast.2021.v08i1.018
}

\begin{abstract}
The whole world is developing into a digitalizing world, whereas the uses of smart phones are rapidly increasing and mobile applications are created in many fields. As well as the field of agriculture is also developing in mobile application. In order to help the farmers in need of help, we have researched some information about mobile application and created an app based on soil analysis. Soil analysis is a major Problem of agriculture \& farming, but their rapid identification remains difficult in many parts of the world due to the lack of the necessary infrastructure. The combination of increasing global smartphone penetration and recent advances in computer vision made possible by deep learning has paved the way for smartphone-assisted soil analyzing, Overall, the approach of training deep learning models on increasingly large and publicly available image datasets presents a clear path toward smartphone-assisted soil analyzing on a massive global scale. Keywords- Mobile application, input, image scanning, Suggestion output
\end{abstract}

\section{INTRODUCTION}

India is an agricultural country with biggest farm sector and giving employment to largest section of the rural population. The Indian monsoon pattern is the driving force for the vast area of arable land (142 million ha) which has necessarily be used for the production of the food grains to meet the demand for domestic and as well as export. India is the second largest populous country of the world. To meet the food demand of its population, scientific development in the field of agriculture is inevitable in order to increase the productivity and production of food grain from the existing land area. Hence there is a vast scope for further development in the field of agriculture. Proverbially, india is known as "Land of Villages". Nearly about 67\% of india's population lives in villages. The occupation of villagers is agriculture. Agriculture is the dominant sector of our economy.

The whole world has been developing towards the smart technology. Nowadays every work has done through the mobile applications, softwares ,IoT etc. Likewise, in agriculture all works have been adapting to the digital format. In agriculture there are many mobile apps related to farm machineries, weather forecasting , marketing, plant disease detection, farm management but there is only a few apps related to soil based testing. The USCS has three major classification groups :(1)coarse grained soil (eg: sands and gravels) (2)Fine grained soils(eg: silt and clay) and (3)Highly organic soils(referred to as peat). The soil also classified based on some more 


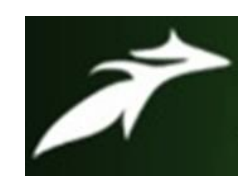

S. Sandhiya et al, International Journal of Advances in Agricultural Science and Technology, Vol.8 Issue.1, January-2021, pg. 139-148

ISSN: 2348-1358

Impact Factor: 6.057

NAAS Rating: 3.77

terms, (1) Soil textures are classified by the fractions of each soil separate (sand, silt, clay ) present in a soil. Soil textures are classified into these twelve types Sand, Loamy sand, Sandy loam, Loam, Silt, Sandy clay loam, Clay loam, Silty clay loam, Sandy clay, Siltyclay, and Clay. (2)Soil structure, There are five major classes of structure seen in soils: Platy, Prismatic, Columnar, Granular, and Blocky. There are also structureless conditions. Some soils have simple structure, each unit being an entity without component smaller units.

It is well known that there are more than 600 cultivated plant species from which there are about 100-200 species play important role in the world trade. However, only 15 plant species represent the most important economic crops. Therefore, these crop species must be classified or grouped in an convenient manner to facilitate communication, dissemination and retrieval of scientific information as well as promotes the conservation and improvement of certain plants . generally, classification of these species is important for these reasons. As the soil testing is a long process from the soil taken upto the results and as well as the suitable crop selection to the land is also a difficult task. Due to this process of delay, We have taken some measures to help the farmers through technology.

\section{LITERATURE SURVEY}

( P.Scull et .al ,2003) has predictive soil mapping can be defined as the development of a numerical or statistical model of the relationship among environmental variables and soil properties, which is then applied to a geographic data base to create a predicitive map.psm is made possible by geo computational technologies developed over the past few decades. For example, advance in geographic information science, digital terrain modelling remote sensing, fuzzy logic has created a tremendous potential for improvement in the way that soil maps are produced.

(Luis Ruiz et.al,2009) has research the aim of the present paper is to review the technical and scientific state of the art of wireless sensor technologies are very promising in several field such as environmental monitoring. Precision agriculture, cold chain control or traceability. The paper focuses on WSN(Wireless sensor networks) and RFID (Radio frequency identifications )presenting the different systems available recent developments and examples of applications, including zigbee based WSN and passive ,semi- passive and active RFID. Future trends of wireless communications in agriculture and food industry are also discussed.

(Manav Singhal et.al ,2011) has said information and communication technology (ICT) in agriculture is an emerging field focusing on the enhancement of agricultural and rural development in India. It involves innovative applications using ICT in the rural domain. The advancement of ICT can be utilized for providing accurate and timely relevant information and services to the farmers, thereby facilitating an environment for remunerative agriculture. This paper describes a mobile based application for farmers which would help them in their farming activities. We propose an android based mobile application -Krishi Ville which would take care of the updates of 


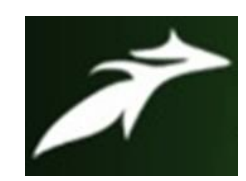

S. Sandhiya et al, International Journal of Advances in Agricultural Science and Technology, Vol.8 Issue.1, January-2021, pg. 139-148

ISSN: 2348-1358

Impact Factor: 6.057

NAAS Rating: 3.77

the different agricultural commodities, weather forecast updates ,agricultural news updates. The application has been designed taking indian farming in consideration.

(Shitala Prasad et.al ,2013) has said today ,use of mobile devices is very common by everyone including the farmers .Introduction of Information and Communication Technologies (ICT) has seen a keen role in daily life of farmers. Earlier ,farmers used to depend on clouds for rains we looking into the Cloud Computing (CC) for their solutions towards cultivation of better crops in modern agricultural world. The conventional methods used by the farmers, particularly in india are very slow and unreliable. The crops are damaged in field itself due to disease attacks and lack of information resources. This loss grows more than $40 \%$ in total annually. This paper proposes various ways in which a farmer can utilize MCC on their handsets using application called Agro mobile to assist them for relatively better cultivation and marketing. The main attention of this work is focused on crop image analysis. Image processing techniques requires large amount of completion power and memory to process for which a mobile devices fails.

(Richard K Lomotey et.al,2013) has said this paper presents a mobile application called Mobi-Crop that aids crop farmers in the application of pesticides . The requirement of the application is to have a monitoring station where updates are constantly being pushed to the farmers who are geographically dispersed. This requirement creates the need to deploy a mobile distributed architecture rather than a standalone app that has become the standard for most existing application in todays mobile economy. We proposed a three-tier architecture consists of mobile devices, a cloud-hosted middleware and cloud storage where the pesticides data which we model as web services are stored. The proposal of the middleware is to reduce the chances of overloading the mobile nodes with Data as well as managing the bandwidth of wireless network efficiently. This is achieved by introducing policy based content delivery of data which necessitates that a farmer receives only the information this is of interest to him/her rather than flooding the farmer's device with all voluminous back-end data.

(Vikas Kumar et.al , 2013) has described mobile devices are used extensively by the people for communication, music, entertainment, internet and social networking. There is a lack of applications, which can be really useful for the professionals to improve their working capabilities. In this paper, we have proposed and implemented an information system for farmers which can be operated on their mobile phones. The system is developed using service oriented architecture (SOA) to process spatial data and knowledge base. The knowledge base is maintained in the form of ontologies. The system is an effort to fill the gap between the farmers and agricultural experts. A farmer can provide inputs related to crops being cultivated and location specific information to get specific suggestions, alerts and recommendations to improve productivity. It will be generated using the knowledge base. Whenever a farmer observes some anomalous behavior for crops or climate, the system is able to 


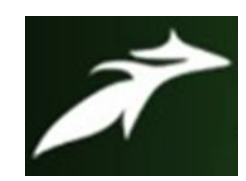

S. Sandhiya et al, International Journal of Advances in Agricultural Science and Technology, Vol.8 Issue.1, January-2021, pg. 139-148

ISSN: 2348-1358

Impact Factor: 6.057

NAAS Rating: 3.77

generate recommendation based on inputs provided. We have resolved some of the queries as a part of on-going work and results are displayed on a android based mobile devices for demonstration of the system.

(Somya Sharma et .al , 2013) has said the agriculture activities have a major role in determining the quality and quantity of agriculture produce. In this paper, we propose a novel mobile sensing based framework which uses machine learning algorithm for the detection of agriculture activities. To collect the sensors data and ground truth an android based mobile application as also been developed and has been provided to the farmers. We investigate the performance naïve bayes, linear discriminant analysis(LDA)and k-Nearest Neighbor(k-NN) classifiers to detect the activities like harvesting, bed making, stand -still and walking. We also use the same classifiers to detect the placement of the mobile phone on the body which will hence provide a degree of freedom to the farmers in placing the mobile phone as per their convenience.

(Joaquin Gutierrez Jaguey et.al , 2015) has researched an automated irrigation sensor was designed and implemented to use in agricultural crops. The sensors uses a smartphone to capture and process digital images of the soil nearby the root zone of the crop, and estimates optically the water contents. The sensor is confined in ana chamber under controlled illumination and buried at the root level of the plants. An android app was developed in the smartphone to operate directly the computing and connectivity components, such as the digital camera and the wifi network. The mobile app wakes up the smartphone, activating the device with user -defined parameters . Then, the built -in camera takes a picture of the soil through an antireflective glass window and an RGB to gray process is achieved to estimate the ratio between wet and dry area of the image. After the wifi connection is enabled, the ratio is transmitted via a router node to a gateway for control an irrigation water pump . Finally the app, sets the smartphone into the sleep mode to preserve its energy. The sensor is powered by rechargeable batteries, charged by photovoltaic panel. The smartphone irrigation sensor was evaluated in a pumpkin crop field along 45 days. The experimental results show that the use of smartphones as an irrigation sensor cloud become a practical tool for agriculture.

(Mohammad Ali Fourati et.al , 2015) has designed and fabrication of in order to support them, recent advances in decision making and wireless sensor technologies offer vast opportunities for agriculture sector development. The present paper aim at the realization of a monitoring Web -Based decision support system communicating with a wireless sensor network for irrigation scheduling in developing countries context. The system goes further and supports the farmers for restructuring agriculture land using geographical information system maps and provides the information needed as the climate and soil measures referring to mathematical, methods and algorithms as the food and agriculture organization's Penman -Monelith method. The analysis, design and implementation of this system are presented to adopt changes of crop design, field location and 


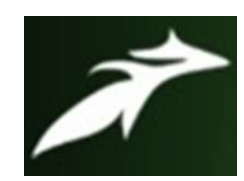

S. Sandhiya et al, International Journal of Advances in Agricultural Science and Technology, Vol.8 Issue.1, January-2021, pg. 139-148

ISSN: 2348-1358

Impact Factor: 6.057

NAAS Rating: 3.77

irrigation patterns taking into account all particularities of such environments constraints as the field conditions, devices availability, etc.

(Hemalata Channe et.al ,2015) has designed development and fabrication Internet -o f- Things and Big data analysis are recent technologies from last few years and applications are being developed in various domains using these as key technologies. Sensor technology has also been advanced and many types of sensors like environmental sensors, gas sensors are developed and used in applications as per the need. Cloud -Computing and Mobile Computing are mature technologies and applications exists in almost every field using those technologies. Uses of these technologies in the field of agriculture are also introduced and are used for improvement in this sector.

(Navdeep Kumar Pal 2016) has defined the colour of leaf corresponds to nitrogen deficiency status of that particular crops, farmers compares colour of leaf with leaf colour chart (LCC) in order to estimate the need of nitrogen fertilizer to their crop. However the ability to compare leaf colour with the LCC varies from person to person that affects the accuracy of final results. The present study proposes a mobile device based applications called "mlcc". Main idea is to simultaneously capture and process a 2-D colour image of rice leaf ,thus elimination the expensive external components, reducing the human color perception and results in achieving the high colour accuracy. This android -based applications correctly identifies the leaf colour up to six levels.

(AG.Abishek et.al ,2016) has described the vision of this project is to ensure fair price to the farming community by devising new techniques and by marketing use of online market. An application, that serves as a platform for movement of agricultural products from the farmers directly to the consumers or retailers. This mobile and web applications provides privilege for both farmers and consumers or retailers to buy and sell the required farm products without the involvement of a middleman at its right profitable price. The agriculture experts shall analyze the product that comes into this platform, approve it an provide ratings based on quality. This makes all the available farm produces easily accessible. Hence it provides freedom of pricing and freedom of access. Through this we can ensure farmers to make selling decisions most advantageously.

(Scott Hirsch et.al ,2016) has experimented systems and methods for developing, customizing and deploying mobile device applications are provides through a mobile applications development and deployment platform, preferably, these systems and methods are implemented in an internet based environment that allows non- technical users to build sophisticated, highly -customizable cross - platform mobile applications. The platform allows users to select, input, create, customize and combine various content, design ,characteristics and application components, such as modules, some which utilize features and functionality associated with various mobile devices and mobile operating systems. In certain embodiments, the platform allows user to compile and 


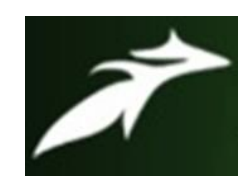

S. Sandhiya et al, International Journal of Advances in Agricultural Science and Technology, Vol.8 Issue.1, January-2021, pg. 139-148

ISSN: 2348-1358

Impact Factor: 6.057

NAAS Rating: 3.77

generate a configuration file for the mobile application that can be distributed to end users for execution on various mobile devices and mobile operating systems.

(Hetal Patel et.al ,2016) has said that india is an agriculture based developing country. Information dissemination to the knowledge intensive agriculture sector is upgraded by mobile - enabled information services and rapid growth of mobile telephony. It bridge the gap between the availability of agricultural input and delivery of agricultural outputs and infrastructure. Mobile computing, cloud computing, machine learning and soft computing are the immerging techniques which are being used in almost all fields of research. Apart from this, they are also useful in our day-to-day activities such as education, medical and agriculture. This paper explores how android apps of agricultural services have impacted the farmers in their farming activities.

(Matt Aitkenhead et.al , 2016) has described soil properties can be used to estimate soil health and suitability for specific land use. These properties include, but are not restricted to, organic matter content, $\mathrm{PH}$, cation exchange capacity, $\mathrm{C} / \mathrm{N}$ ratio, texture and structure. These properties provide broad information about the capacity of the soil to provide nutrients, water and physical support to crops. They also provide information about soil erosion and compaction risk. The measurement of these properties is traditionally carried out through laboratory analysis which delays decision-making. Some of these properties can be estimated from an understanding of the soil-forming characteristics and visual analysis of the soil profile. Here, a method is presented that automates estimating soil fertility properties using image analysis of field-based topsoil images, including image morpho metrics.

(Paul A Venturelli et.al , 2017) has said that recreational fisheries surveys are limited in time and place in many countries. This lack of data limits scientific understanding and sustainable management. Smartphone applications allow anglers to record the details of their fishing trips and catches. In this study, we describe the opportunities and challenges associated with angler apps as a source of recreational fisheries data and propose minimum standards for data collection via angler apps . Realizing this potential requires that we address significant challenges related to angular recruitment and retention, data quality, bias and integration with existing fisheries program. We propose solutions to each of these challenges. These standards relate to trips and catches, angular demographics and behavior should supported through consultation and research. Angler apps have the potential to fundamentally change how anglers intract with the resources and with management.

(Jorge Adelgado et.al ,2017) has said that Nitrogen fertilizer from organic and inorganic sources is used across the world's agro ecosystems. It contributed to higher yields and higher economic returns to farmers, and is essential for food security. Nitrogen tools can help us assess the risk of nitrogen losses from a field to the environment and increases nitrogen use efficiencies. This new advancement portable technology will enable the use 


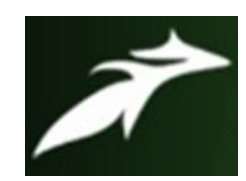

S. Sandhiya et al, International Journal of Advances in Agricultural Science and Technology, Vol.8 Issue.1, January-2021, pg. 139-148

ISSN: 2348-1358

Impact Factor: 6.057

NAAS Rating: 3.77

of small devices such as smart phones to conduct an assessment on site and visit with farmer at any given field site where a wireless connection is available. The nitrogen index is a quick tool and its assessments of nitrogen loss risk are correlated with observed values. This is the first nitrogen index app in the world and it's the beginning of more advances to come in the field of portable agricultural technology.

(P.Goncharov et.al ,2018) has suggested plant disease detection by using different machine learning techniques is very popular field of study. Many promising results were already obtained but its still only few real life easier. The aim of our research solving the problem of detection and preventing diseases of agricultural crops. We considered several models to identify the most appropriate deep learning architecture. As a source of the training data ,we use the plant village open data base. During research ,the problem with plant village images collection was detected. The synthetic nature of the collection can seriously affect the accuracy of the neural model while processing real life images. We collected a special data base of graph leafs consisting of four set images.

(P.Ferentinos,2018) in this paper, convolutional neural network models were developed to perform plant disease detection and diagnoses using simple leaves images of healthy and diseased plants through deep learning methodologies. Training of the model was performed with the use of an open data base of 87.848 images containing 25 different plants in a set of 58 district classes of combinations, including healthy plants. The significantly high success rate makes the model the very useful advisory or early warning tool and an approach that could be further expanded to support an integrated plant disease identification system operate in real cultivation condition.

(Katty Lagos Ortiz et.al ,2018) has informed communications, technology play an important role in the agriculture sector due to it helps to perform activities such as agricultural re-sources management. The efficiency in the crop production i.e. produce more with less, is a challenge that must be addressed. Smart phones and mobile applications have become part of the daily lives of people. Hence, it's important to adopt these technologies for performing daily agriculture tasks. This work presents an evaluation and comparison of mobile applications for agriculture have become part of the daily lives of the people.

(Muhammad Toseef ,Malik Jahan Khan,2018) has said one of the main problems being faced by agriculture sector in Pakistan and other developing countries is that crop disease are not diagnosed timely and efficiently. Conventional methods for disease diagnoses in crops lead to less accurate and inefficient diagnosis, consequently leading low productivity .In this paper, an intelligent approach for the diagnosis of crop diseases is proposed which is capable of working over android mobile devices using fuzzy inference system as the decision making engine at the back end. The system capable enough to communicate to the farmers in Pakistan in their local language urdu and assist them in diagnosing diseases in their crops. The proposed system has been tested on pool of hundred real 


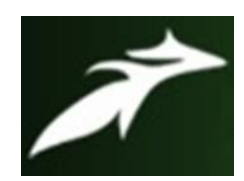

S. Sandhiya et al, International Journal of Advances in Agricultural Science and Technology, Vol.8 Issue.1, January-2021, pg. 139-148

ISSN: 2348-1358

Impact Factor: 6.057

NAAS Rating: 3.77

crop problems and its inference engine has shown excellent performance in prediction of the right disease which is up to $99 \%$ accurate.

(Apeksha C.Dhageet.al,2018) has defined we aim to focus on spreading awareness about the agriculture scheme ,new forming technique to access easily agriculture related documents such as 7/12,8A in their villages to provide crop related updated information. To guide suitable fertilizer for crop and updating with market rate information. Agriculture is considered to be a main occupation for a most segment of population. There is a large gap between rural areas and information residing in agricultural knowledge centre. E-Agriculture is a rising field focusing on the improvement of agriculture and rural development through communication process and advanced information and technology.

(Arts Picon et.al ,2019) has said over the last years , a number of image analysis -based methodologies have been proposed for automatic image disease identification. Among these methods, the use of deep convolutional neural (CNNs) has proven tremendously successful for different visual classification tasks. This work analyses the performance of early identification of three relevant European endemic wheat disease tan spot and rust. The analysis was done using different mobile devices and more than 8178 images were captured in two pilot sites in Spain and Germany during 2014,2015 and 2016 .

(Rajini Agashe et.al ,2019) has described about kishan suvidha app. In transfer of latest technical information regarding agriculture to farmers of the district. The kisan suvidha app was developed for transfer of quick timely and need based appropriate information regarding agriculture and allied sectors. Regarding applicability of the information received through app, it was found that $52 \%$ of the respondents reported that information received was applicable in crop production, satiation , need based, timely and content was readable. Need based information and timeliness was useful i.e. $84 \%$ and visibility of content was $94 \%$ regarding social media.

(Sarjeet Kaur et.al ,2020) has described soil health and fertility is the representative for sustained high crop productivity and profitability of the farmers. Although soil testing is a regular feature of the department of agriculture cooperation and farmers welfare but after the launch of soil health card scheme, soil testing is taken up on a machine mode. Finding the study revealed that majority of the beneficiaries had knowledge regarding ideal time for the collection of soil sample from the place where a heap of FYM is not placed. Difficulty in operating internet to access soil health card portal, delay in receiving SHC and lack of mobile soil testing vans were major constrains faced by the farmers in the application of SHC. 


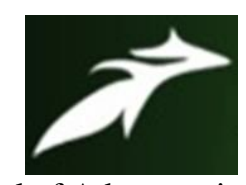

S. Sandhiya et al, International Journal of Advances in Agricultural Science and Technology, Vol.8 Issue.1, January-2021,pg. 139-148

ISSN: 2348-1358

Impact Factor: 6.057

NAAS Rating: 3.77

\section{REVIEW OF LITERATURE}

From all those literature review, we have searched and identified some problems whereas,

* There are most of the farmers are uneducated, so they face trouble in languages.

* These modern technologies are not reachable in rural areas, some apps are native apps and web apps they are insufficient on devices.

* To overcome all those criteria, we design our project to reduce the separate soil laboratory, wastage of soil.

* To prevent the unwanted uses of seeds. And It's an economical and easily affordable for all kind of farmers.

\section{CONCLUSION}

$>$ Till now the farmers are struggling to analyze the soil type, from this app we can rectify the problem.

$>$ Using a public dataset of 54,306 images of soil types crop varieties which are suitable to that land collected under controlled conditions,

$>$ Most of the farmers has to test their soils in laboratories but using this app they can easily test their soil type.

$>$ As the traditional farmers are decreasing in farming this helps the upcoming farmers to farm in the future

\section{References}

[1]. AG.Abishek, M.Bharathwaj, L.Bhagyalakshmi,2016,Agriculture marketing using web and mobile based technologies, IEEE Technological innovations in ICT for agriculture and rural Development(TIAR), vol 41-44.

[2]. Andrea Sinche-Guzman.Katty Lagos-Ortiz.Jose Medina,Moreira,MayraGarzon,Gova Vanessa ,2018, mobile application for crop management, international conference on technologies and innovations, vol.57-69.

[3]. Apeksha C.Dhage ,Sakshi J.Bhake ,Shilpa A. Hedau ,Devendra V. Baywar, Sarang K.Hulkey ,Prof. Manoj R. Sayankar,2018,A progress paper on kisan Agro yojana ,IJSRSET,vol 4.

[4]. ArtzaiPicon,Aitor Alvarez Gila,Maximiliam Seitz,Amaia Ortiz Barredo.JoneEchaZarra, 2019,Deep conventional neural networks for mobile capture device,based crop disease classification in the wild,computers and electronics in agriculture,vol.208.209.

[5]. ArtzaiPicon,Aitor Alvarez Gila,Maximiliam Seitz,Amaia Ortiz Barredo.JoneEchaZarra, 2019,Deep conventional neural networks for mobile capture device, based crop disease classification in the wild, computers and electronics in agriculture,vol.208.209.

[6]. HemlataChanne.SukeshKothari.DipaliKadam,2015,multi disciplinary model smart agriculture using IoT Sensors, cloud, computing mobile computing and big data analysis, computer technology and application,vol.6(3). 


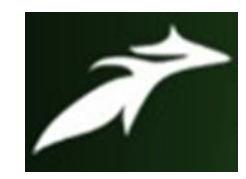

S. Sandhiya et al, International Journal of Advances in Agricultural Science and Technology, Vol.8 Issue.1, January-2021, pg. 139-148

ISSN: 2348-1358

Impact Factor: 6.057

NAAS Rating: 3.77

[7]. Hetal Patel and Dr.Dharmendra Patel2016,survey of android app for agriculture sector Journal of information sciences technology.

[8]. Joaquin Gutierrez Jaguey, Juan Francisco Villa Medina, Aracely Lopez-Guzman, Miquel Angel, 2015,Smartphone irrigation Sensor, IEEE sensors journal,vol15(9)

[9]. Jorge A Delgado, Kevin Kowalski,Caleb Tebbe,2013, The first nitrogen index app for mobile devices; using portable technology for smart agriculture management computers and electronics in agriculture, vol.91.

[10].Luiz Ruiz,Garcia Loredana,Lunadei, Pilar Barrerio,Ignacio Robla,2009, A review of wireless sensor technologies and applications in agriculture and food industry : State of the art and current trends, vol9( 6).

[11].Matt Aitkenhead,David Donnelly,Malcolm Coull,Richard Gwatkin,2016,Estimating soil properties with a mobile phone digital soil morphometrics.

[12]. Mohammad Ali Fourati.Wailid C Hebbi.AnasKamoun,2014,development of web based weather station for irrigation scheduling,3rd IEEE International colloquium in information science and technology,vol.3.7-42.

[13]. Muhammaed Tossef ,Malik Jahan Khan,2018, An intelligent mobile application for diagnosis of crop diseases in Pakistan using fuzzy inference system, Coumputers and electronics in agriculture, vol 153,1-11.

[14]. Navadeep Kaur,2016,Design and development of a mobile application to investigate leaf nitrogen content with image processing techniques,Punjab agricultural university, Ludhiana

[15].P. Sucull, J.Franklin,2003, predictive soil mapping, vol 17.

[16].P.Ferentinos,2018, Deep learning models for plant disease detection and diagnosis,vol.145.

[17].P.Goncharonvmg ,Ososkovchaevskilya,Nechaevskiya Uzhinskiyai, Nestsiarenia,2018,Disease detection on the plant leaves by deep learning, advances in neural computing, Machine learning and cognitive research,151-159.

[18].Paul A Venturelli, Kieran Hyder,Christian Skov,2017,Angler apps as a source of recreational fisheries data: opportunities, challenges and proposed standards, Fish of fisheries, vol 18(3) 578-595.

[19].Rajini Agashe, SachinmVerma, Pradeep Singh,2019,Opinion of farmers regarding effectiveness of information dissemination through kisan suvidha mobile application in surguja district of Chhattisgarh-Journal of krishi viyan,vol-7.

[20].Richard K Lomotey,YidingChai.KaziAAhmed.Ralph Deters,2013,Webservices mobile application for geographically dispersedo crop farmers, IEEE 16th International conference on computational science and engineering,vol.151-158.

[21]. Sarvjeet Kaurl, Prabhjot Kaurl, Pankaj Kumar, 2020,Farmers knowledge of soil health card and constrains in its use,Indian journal of extension education, vol 56.

[22].Scott Hirsch, Areasen Pereymeer,Sunny Rajpal,2016, Studying mobile app for agriculture, Systems and methods for mobile application development, vol 8 .

[23].Shitala Prasad,Sateesh k.Peddoju Debasis Ghosh,2013,Agromobile: A cloud based framework for agriculturist on mobile platform, International journal of advanced science and technology, vol.59.

[24]. Somya Sharma, Jabal Raval, Bhushan Jagyasi, 2013, mobile sensing for agriculture activities detection, IEEE global humanitarian technology conference, 337-342.

[25]. Vikas Kumar, Vishal Deve, Rohan Nagrani, Sanjay Chaudhary Minal Bhise, 2013, Crop cultivating information system on mobile devices, IEEE Global humanitarian technology conference; south Asia satellite, 196-202. 